Revue d'histoire de l'Amérique française

BEVUE D.HISTOIRE DE L'AMÉRIQUE FRANÇAISE

\title{
JAMES, William C., A Fur Trader's Photographs. A. A. Chersterfield in the District of Ungava, 1901-4. Kingston et Montréal, McGill-Queen's University Press, 1985. xiv-114 p. $24,95 \$$
}

\section{John A. Dickinson}

Volume 41, numéro 4, printemps 1988

URI : https://id.erudit.org/iderudit/304641ar

DOI : https://doi.org/10.7202/304641ar

Aller au sommaire du numéro

Éditeur(s)

Institut d'histoire de l'Amérique française

ISSN

0035-2357 (imprimé)

1492-1383 (numérique)

Découvrir la revue

Citer ce compte rendu

Dickinson, J. A. (1988). Compte rendu de [JAMES, William C., A Fur Trader's Photographs. A. A. Chersterfield in the District of Ungava, 1901-4. Kingston et Montréal, McGill-Queen’s University Press, 1985. xiv-114 p. 24,95 \$]. Revue d'histoire de l'Amérique française, 41(4), 636-636.

https://doi.org/10.7202/304641ar d'utilisation que vous pouvez consulter en ligne.

https://apropos.erudit.org/fr/usagers/politique-dutilisation/ 
JAMES, William C., A Fur Trader's Photographs. A. A. Chersterfield in the District of Ungava, 1901-4. Kingston et Montréal, McGill-Queen's University Press, 1985 . xiv-114 p. 24,95\$

Ce bel album sur la vie des Cris et celle des Inuit du nord québécois au tournant du siècle est l'oeuvre d'un jeune facteur de la Compagnie de la Baie d'Hudson, Albert (Bert) Chesterfield. Arrivé au Canada de son Kent natif à l'âge de quinze ans, rien ne prédisposait cet orphelin à une carrière dans la toundra canadienne. Cependant, malgré l'offre de son oncle de lui payer des études à McGill, Bert Chesterfield s'engagea comme apprenti clerc et fut envoyé apprendre son métier au poste de Rigolet sur la Côte du Labrador en 1895. C'est là qu'il commença à s'intéresser à la photographie, mais son talent pour cet art ne se développa pleinement qu'après 1901 lorsqu'il assuma la charge de facteur au Poste-de-la-Baleine sur la baie d'Hudson. Les images reproduites dans ce livre furent toutes prises entre 1901 et 1904 lorsqu'il occupa cette fonction.

Au début du siècle, le Poste-de-la-Baleine était le comptoir de traite le plus septentrional de la côte est de la baie d'Hudson et attirait aussi bien les Inuit de la côte et des îles Belcher que les Cris de l'intérieur. L'organisation du livre met en évidence les trois composantes de la vie de cette région: dans un premier temps il est question des établissements européens; suit l'étude des Inuit; et enfin celle des Cris. Les documents iconographiques sont d'une très grande qualité et permettent d'apprécier la civilisation matérielle, les activités de subsistance et certaines coutumes des autochtones de cette époque. Outre les iglous et tentes, raquettes, canots et kayaks, les vêtements et parures, on peut examiner les méthodes de chasse au phoque et de construction de canots. L'autochtone est également mis en vedette dans une série de portraits.

Ces photos mettent également en lumière les effets néfastes de la présence européenne sur la vie des autochtones. Les Inuit qui venaient d'être intégrés dans le circuit commercial à cette époque, avaient peu souffert des influences des marchands de pelleteries. Ils étaient encore robustes et en santé tandis que les Cris avaient manifestement beaucoup souffert des maladies européennes et de la famine résultant d'une chasse trop intensive. La civilisation matérielle des Inuit était également plus «traditionnelle» avec très peu d'apports européens tandis que les Cris s'habillaient déjà avec des tissus importés.

La présentation de William James est sobre, complète et constitue une belle introduction à la vie du photographe et, surtout, des autochtones du nord québécois au tournant du siècle. 